July 1936, and is still producing at the rate of approximately 10 barrels a day. Another situated half a mile south-east gave a 30-barrel show of oil in the Bartesville Sand in 1922 ; and a third, a considerable distance to the north-east of the other two, produced about 25 barrels of oil in 1921. The presence of productive oil sand in these three wells points to the probability that oil-bearing Bartesville Sand occurs in this district in a characteristic lens-shaped body. In addition, there are known to be in the Reservation two small domes, as yet untested, but structurally similar to two nearby domes producing from the Siliceous Lime. The productive domes are fairly typical of the oil fields, being of small extent but giving large yields. On one of these there are eight wells which have yielded oil, and on the other five. The approximate yield per acre of the former dome up to July 1936 was 6,964 barrels of oil, and of the latter, for the same period, 6,300 barrels. Recently, also, the rate of yield from both domes has been materially increased by treating the oil-bearing beds in the upper part of the Siliceous Lime with hydrochlorie acid.

\section{Plastics and Insulation}

A JorNT meeting of the Institution of Electrical Engineers and the Plastics Group of the Society of Chemical Industry was held at the Institution of Electrical Engineers on March 24 to discuss a paper on "Plastics and Insulation" by L. Hartshorn, N. J. L. Megson and E. Rushton. It is largely based on an investigation carried out at the National Physical Laboratory and the Chemical Research Laboratory for the British Electrical and Allied Industries Research Association. Broadly speaking, a plastic is any material from which rigid objects of predetermined shape may be made by moulding processes. Their most characteristic property is that by suitable treatment they may be made to pass through a plastic condition, that is, a state between the solid and liquid states, like that of dough or damp clay. The property of hardening instead of softening on the application of heat is one of considerable practical importance to both moulders and users of plastics. It increases the working temperature of the material and improves its mechanical properties. It also allows the finished article to be removed from the mould while still hot. The primary function of an electrical insulating material (a dielectric) is to act as a barrier to the flow of electricity. Dielectrics always pass a leakage current, sometimes through the body of the material and sometimes over its surface. These currents can be taken as a measure of a defect of the material. With alternating current we have in addition an expenditure of energy due to the pulsating current in the dielectric. Polystyrene and polyindene, materials not yet produced in Great Britain, are hydrocarbon plastics, made in the form of clear glass, like solids, and are almost ideal for use in cables for high-frequency work ; for example, in television, and in ultra-shortwave radio work, and in junctions for high-voltage cable work they are almost ideal.

\section{Report on Street Lighting}

DR. J. W. T. WALSH gave an introductory account to the Illuminating Engineering Society on February 8 of the final report of the Ministry of Transport Committee. It was then discussed by the Society and the discussion is published in the February issue of Light and Lighting. The members constituting the Committee were the chairman, four lighting specialists, two engineers associated with local authorities and two Government officials. Its final report was issued in November 1937. The Committee received evidence from several organizations and made inspections of a large number of existing installations. It also carried out experimental work on a special roadway (Lonsdale Road, Barnes) set aside for the purpose. The Committee classified roads into two groups only, $A$ and $B$, and gave technical recommendations for each group. In the recommendations the Committee insisted on the importance of satisfactory maintenance and approved of lighting from dusk to dawn. Whilst it was recognized that special study of measures for the guidance of traffic during fog was necessary, it was urged that the general design of installations should not be prejudiced by special adaptation to fog conditions. The report also recommends that a formal specification for street lighting should be issued without delay by the British Standards Institution. In conclusion, Dr. Walsh showed a film of a lighted street just as it would appear in practice, in which various objects (persons stepping into the roadway, dogs, etc.) were continually coming into view and then disappearing. The number of such disappearances was stated to be fifty-six. But very few of the observers succeeded in identifying half this number. This showed the danger of bad lighting.

\section{Journal of Neurophysiology}

THE new Journal of Neurophysiology, under the editorship of Prof. Dusser de Barenne, J. F. Fulton and $\mathbf{R}$. W. Gerard, made its first appearance in January. It is designed primarily to provide a means of publishing papers dealing with the experimental analysis of the phenomena of the central and peripheral nervous system, and descriptive neuroanatomy and pathology are intentionally excluded. The publisher, Thomas of Springfield, Illinois, intends to produce a number every other month, and the editorial board undertakes to deal with submitted papers within one or two months of receipt. This accelerated publication is certainly desirable, as the existing channels for the publication of papers in this field in the United States are overcrowded, and there is an inevitable delay. The first number, of 55 pages, contains nine papers dealing, inter alia, with cerebral action potentials, effects of experimental cerebral lesions, degeneration of nerve, and changes in the salt content of nerves as a result of the transmission of impulses. The format is pleasing, and the standard of the illustrations is high. A little more uniformity in certain details is desirable; authors are cited in different papers either by numbers, by year or by an abbreviation of the year ; the date of 
receipt of papers is not always given. A more uniform lettering of the illustrations might also receive attention, and the adoption of a bold face type for the volume numbers in the lists of references would add to the ease of reading. These criticisms are, however, minor and are points which will probably be dealt with as the journal becomes more mature. The periodical certainly fills a need, and should serve, as the editors point out, actually to help to counteract undue subdivision in physiology by bringing together in one journal many divergent investigations on the nervous system.

\section{Social Applications of Physics}

IN an address on the "Social Applications of Physics" at a symposium at the University of Sydney on September 21, which was published in the Union Recorder (October 7), Prof. O. U. Vonwiller, pointing out that the man of science to-day must consider the bearing of his work on the problems of civilization and recognize his responsibility for some of the economic and social difficulties of the times, suggested these difficulties were due primarily to our inability to accommodate social and economic conditions to the rapidly changing methods of production following the application of scientific discovery. The main cause of these rapid changes was the changed status of the inventor, and while the success of the man of science as inventor had brought many real benefits to mankind, much distress had also arisen because in applying scientific discovery the first consideration was that of financial benefit. Prof. Vonwiller considered we could not continue to ignore ameliorating measures and suggested that the most promising method for dealing with the evils of over-production was to reduce the hours of employment. No satisfactory and lasting improvement in our difficulties could be expected, however, unless we adopted much from the methods of scientific investigation and discovery, with their honesty of inquiry and statement. In economic questions the difficulty of avoiding prejudice, however, was very great, and Prof. Vonwiller did not suggest that the adoption of scientific method would remove all our difficulties, though he appealed strongly for a courageous endeavour to understand and make understood the possibilities and limitations of scientific progress.

\section{Twenty-fifth Anniversary of Laue Diagrams}

LAUE first used his method of $\mathrm{X}$-ray analysis of crystal structure in 1912. The twenty-fifth anniversary of this event has been celebrated by Die Naturvissenschaften by the publication of two interesting articles on the progress made in this branch of crystal chemistry. One, by F. Laves (Naturwiss., 25, 705, 721; 1937), deals with the theory of the method and its development, and mentions its applications, particularly to the determination of atomic distances in crystals. A full account of our present knowledge of the radii of ions and atoms and their separations in crystals, and the dependence of these on the type of linking, is given, and there is a useful bibliography. The second article deals with the use of X-ray interference methods in the investigation of the fine-structure of animal tissues, and is contributed by F. O. Schmitt (Naturwiss., 25, 709 ; 1937). It mentions particularly progress made in the examination of nerve, sinew and muscle, and other tissues in which there is a high degree of orientation of proteins or lipins. It will be recalled that Current Science also had special articles in connexion with this anniversary (see NATURE, 139, 517 ; 1937).

\section{History of Science and Medicine}

WE have received the fourth volume of Osiris, a journal edited by Dr. George Sarton and dealing with the history and philosophy of science. This volume is entitled "Incunabula Scientifica et Medica", by A. C. Klebs, and contains the titles of books on science and medicine printed up to the year 1500 , with references to catalogues indicating where the books may be found. This list is very convenient to students of the history of science and medicine, since it contains information which was previously to be found only in large and expensive library catalogues. The volume is quite a substantial one, having 359 pages, so that it is evident that an unexpected range of material of this class was printed at an early period. In a book purporting to give accurate information on dates of publications, it is somewhat surprising to find the title-page dated 1938, whereas the volume was received in October 1937.

\section{Proposed List of Current Geographical Publications}

More than eight hundred technical and scientific periodicals are received by the library of the American Geographical Society. From these a careful selection of material of geographical interest is made, to be entered in the library's research catalogue. A current index is thereby provided to an extremely important body of geographical material that does not appear in the usual library catalogue. There is thus afforded a continuous, up-to-date record of current material of value not only to geographers but also to geologists, economists, anthropologists, and workers in many other allied fields. So useful has the research catalogue proved to the staff of the Society and to those consult: ing its library that the Society now proposes to make this material more generally available if there is sufficient demand. It is planned to publish ten mimeographed lists a year of the material catalogued during the month (material for July and August to be listed in the following issues). The subscription rate will be $\mathbf{3 . 7 5}$ dollars.

\section{Fisheries Research in Australia}

THE 138-ton motor ship Warreen (an aboriginal name for the sea), built for the fisheries section of the Australian Council for Scientific and Industrial Research, has been launched in Melbourne. The vessel will be used for the study of pelagic fish in the waters around Australia, commencing in the south-eastern seas. The headquarters of the section will be at Port 